\title{
Evolution of Microstructure and Microtexture in Friction Stir Welded Oxide Dispersion Strengthened Steel
}

\author{
B.W. Baker, E.S.K. Menon, and L.N. Brewer \\ Mechanical and Aerospace Engineering Department, Naval Postgraduate School, Monterey, CA, USA
}

The high temperature material properties of oxide dispersion strengthened steels (ODS) such as MA956 make them attractive candidates for fusion energy applications; however traditional joining techniques are unsuitable for these alloys due to agglomeration of oxide particles during welding[1]. A lthough friction stir welding (FSW) has been shown as an effective joining mechanism for ODS alloys, the effects of varying welding parameters on e volved microstructure has not been analyzed[2]. In this research electron backscatter diffraction (EBSD) and energy dispersive x-ray spectroscopy (EDS) were used to determine the grain size, grain orientation, microtexture, and oxide particle distribution for three different welding conditions of varying heat input.

MA956 (Fe-19.9Cr-4.75Al-0.4Ti-0.5 $\mathrm{Y}_{2} \mathrm{O}_{3}$ ) was friction stir welded with eight combinations of tool rotational speed and tool traverse speed. Three of these conditions produced consolidated defect free welds; the microstructures of which were analyzed by EBSD and EDS. Cross sections across the weld path were prepared by standard metallographic techniques and electropolishing. Analyses were completed using a Zeiss Neon 40 field emission gun scanning electron microscope at $20 \mathrm{keV}$ beam voltage, $60 \mu \mathrm{m}$ objective aperture, and a probe current of $1 \mathrm{nA}$. The EBSD signal was collected and analyzed using the OIM 6.0 software with a Hikari high speed camera.

FSW caused significant grain coarsening in the weld nugget with grain sizes increasing from $0.89 \mu \mathrm{m}$ in the base metal (BM) to a maximum of $12.5 \mu \mathrm{m}$ in the stir zone (SZ) for the highest heat input condition. Grain growth increased as the heat input increased with no a bnormal grain growth noted. L arge gradients in grain size were found in the advancing side of the thermomechanically affected zone (TMAZ) for each condition and the magnitude of these gradients increased with increasing heat input (Figure 1). Grains in the weld nugget were near-equiaxed with approximately $20 \%$ low angle grain boundaries (less than 10 degrees) indicating continuous dynamic recrystallization. This indication was further supported by the observation of a persistent simple shear texture in the weld nugget for all welding conditions (Figure 2)[3]. Complex yttrium-aluminum-oxide particles such as yttrium aluminum monoclinic and yttrium aluminum perovskite exist in MA956 originating from reactions of the original $\mathrm{Y}_{2} \mathrm{O}_{3}$ powders with oxidized aluminum during the manufacturing process[4]. $\mathrm{T}$ hese oxides were observed to coarsen in the weld nugget as heat input during FSW is increased growing in average size from $160 \mathrm{~nm}$ in low heat input conditions to $345 \mathrm{~nm}$ for high heat input conditions (Figure 3).

The results show important microstructural effects that are a function of heat input associated with FSW. Both ferrite grains and yttrium-aluminum oxides in the weld nugget are coarsened by higher heat input conditions. A nalysis of the strengthening mechanisms indicates that Hall-Petch grain boundary strengthening is the dominant mechanism. High heat input conditions produce large gradients in material properties (most notably grain size but also particle size and hardness) in the TMAZ that are potential areas of failure. The heat input from FSW causes oxide particle coarsening due to Ostwald ripening. Together these results show that FSW is a viable joining mechanism for ODS alloys, although judicious selection of welding parameters may be necessary to avoid degradation of material properties. 
References:

[1] M. McKimpson and D. Odonnell, "Joining ODS materials for high-temperature applications," Journal of the Minerals Metals \& Materials Society, vol. 46, pp. 49-51, Jul 1994.

[2] S. Noh, et al., "Microstructure and mechanical properties of friction stir processed ODS ferritic steels," Journal of Nuclear Materials, vol. 417, pp. 245-248, Oct 12011.

[3] J. Baczynski and J. J. Jonas, "Texture development during the torsion testing of alpha-iron and two IF steels," Acta Materialia, vol. 44, pp. 4273-4288, Nov 1996.

[4] L. L. Hsiung, et al., "Formation mechanism and the role of nanoparticles in Fe-Cr ODS steels developed for radiation tolerance," Physical Review B, vol. 82, Nov 92010.

a)

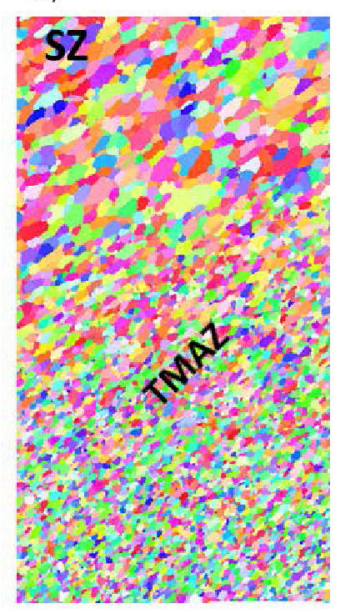

b)

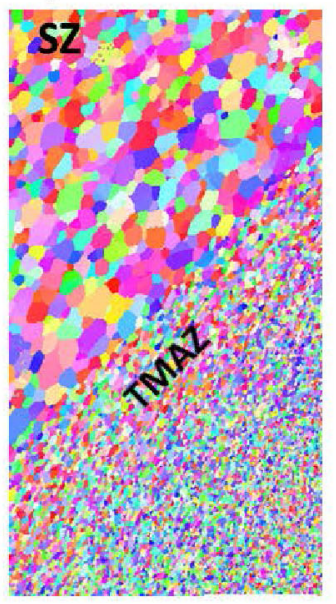

c)

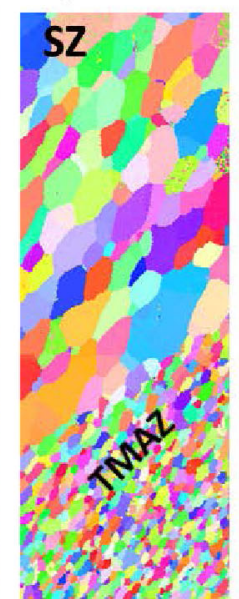

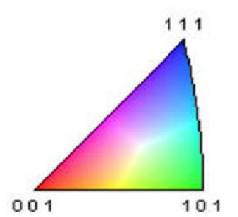

100 microns

Figure 1. Inverse pole figure maps of the stir zone-TMAZ boundary for (a) low, (b) moderate, and (c) high heat input conditions (inverse pole figure orientation along weld direction).
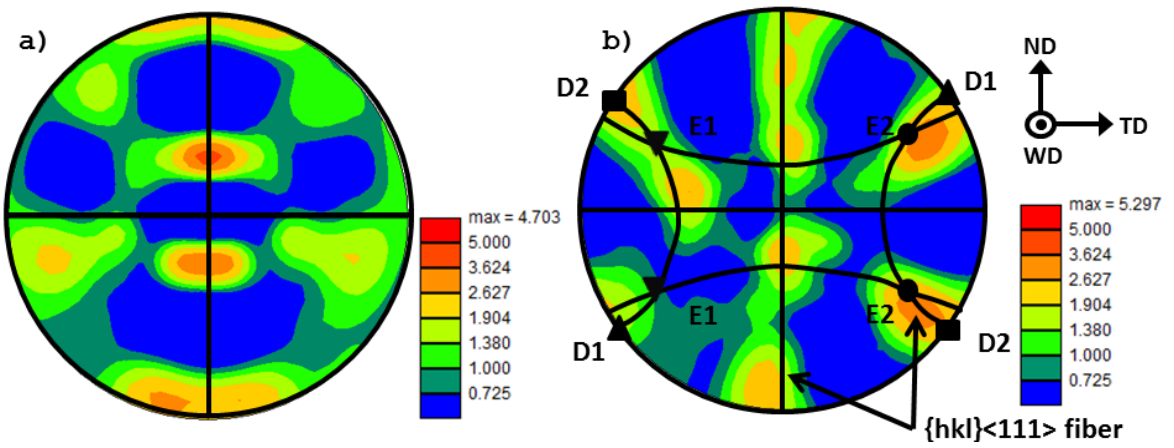

Figure 2. EBSD pole figures of (a) base metal rolling texture and (b) weld nugget. Ideal torsional texture for ferrite overlaid from Baczynski[3].

a)

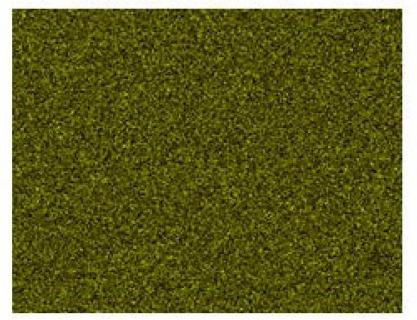

b)

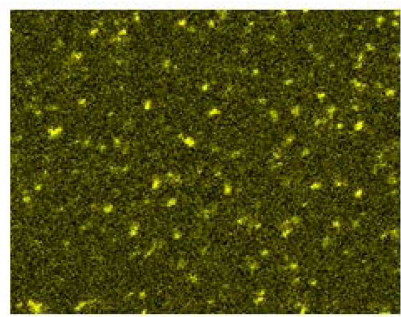

C)

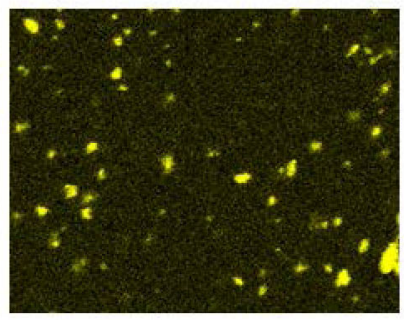

10 microns

Figure 3. Yttrium L- $\alpha$ x-ray maps for (a) base metal, (b) low heat input, and (c) high heat input conditions showing yttrium-aluminum-oxide particle coarsening during FSW. 